\title{
Factors Associated with an Unhealthy Lifestyle among Adults in Riyadh City, Saudi Arabia
}

\author{
AlJohara M. AlQuaiz ${ }^{1,2}$, Ambreen Kazi ${ }^{1,2, *}$, Turky H. Almigbal ${ }^{2}$, Ali M. AlHazmi ${ }^{2}$, Riaz Qureshi ${ }^{1,2}$ \\ and Khaled M. AlHabeeb ${ }^{1}$ \\ 1 Princess Nora Bent Abdullah Research Chair for Women's Health Research, King Saud University, \\ Riyadh 11321, Saudi Arabia; jalquaiz@ksu.edu.sa (A.M.A.); riaz.qureshi9@gmail.com (R.Q.); \\ kmh-100@hotmail.com (K.M.A.) \\ 2 Department of Family \& Community Medicine, College of Medicine, King Saud Medical City, King Saud \\ University, Riyadh 11321, Saudi Arabia; Almogbal@yahoo.com (T.H.A.); aalhazmii@ksu.edu.sa (A.M.A.) \\ * Correspondence: akamran@ksu.edu.sa; Tel.: +966-1-4692714
}

Citation: AlQuaiz, A.M.; Kazi, A.; Almigbal, T.H.; AlHazmi, A.M.; Qureshi, R.; AlHabeeb, K.M. Factors Associated with an Unhealthy Lifestyle among Adults in Riyadh City, Saudi Arabia. Healthcare 2021, 9, 221. https://doi.org/10.3390/ healthcare 9020221

Academic Editor: Pedram Sendi

Received: 14 January 2021

Accepted: 15 February 2021

Published: 17 February 2021

Publisher's Note: MDPI stays neutral with regard to jurisdictional claims in published maps and institutional affiliations.

Copyright: (c) 2021 by the authors. Licensee MDPI, Basel, Switzerland. This article is an open access article distributed under the terms and conditions of the Creative Commons Attribution (CC BY) license (https:// creativecommons.org/licenses/by/ $4.0 /)$.

\begin{abstract}
Background: Unhealthy lifestyles are a global concern. This study measured the prevalence and factors associated with an unhealthy lifestyle in Riyadh city, Saudi Arabia. Methods: An interviewbased, cross-sectional study was conducted with 968 males and 2029 females, aged 30-75 years, covering 18 primary health care centers in Riyadh. Multivariate logistic regression analyses were conducted to identify the significant determinants associated with an unhealthy lifestyle. Results: Overall, men were $1.49(1.28,1.74)$ times at higher risk of an unhealthy lifestyle compared to women. Men reporting unhealthy lifestyle were $2.1(1.3,3.4)$ and $1.5(1.0,2.6)$ times more likely than men with healthy lifestyle to cite not enjoying physical activity, lack of social support, and not having enough information about a healthy diet $[1.5(1.0,2.0)]$, whereas those $\geq 45$ years age group were 30 times less likely to report unhealthy lifestyle $[0.7(0.5,0.9)]$. In contrast, in women aged $\geq 45$ years $[1.3(1.1,1.7)]$, lack of motivation [1.3 $(1.1,1.7)]$, feeling conscious while exercising [2.0 (1.4, 2.9)], not enjoying healthy food $[1.6(1.3,2.1)]$ and no family support to prepare healthy food $[1.4(1.1,1.8)]$ were significantly associated with an unhealthy lifestyle. Conclusions: In a Saudi sample, younger men and older women are at higher risk of an unhealthy lifestyle. In addition to self-motivation, combined strategies to promote physical activity and healthy eating are required to improve lifestyle.
\end{abstract}

Keywords: age; unhealthy lifestyle; physical activity; healthy diet; Saudi Arabia

\section{Introduction}

According to the World Health Organization (WHO), the behavioral factors associated with an unhealthy lifestyle include the consumption of a diet with inadequate fruit and vegetables, tobacco smoking, physical inactivity, a sedentary lifestyle, and alcohol consumption [1]. The literature identifies the fact that people who exercise and eat healthy food have a higher chance of living a healthy lifestyle and are at less risk of getting chronic diseases like type 2 diabetes, hypertension, and cardiovascular diseases [2,3].

Globally, the unhealthy lifestyle is becoming more prevalent, with physical inactivity ranging from $43 \%$ in the United States of America and the Middle East to $17 \%$ in Southeast Asia [3,4]. A national-level study from Saudi Arabia found that the prevalence of total physical inactivity in men versus women, aged 15 to 64 years, was $60 \%$ and $73 \%$, respectively [5]. Attractive advertisements and conveniently available fast and processed foods have reduced the consumption of a healthy and fresh diet such as vegetables and fruits [6]. Moreover, the prevalence of smoking has increased, especially among young adults. In addition to cigarettes, the use of other dangerous forms of tobacco smoking, such as water pipe, vapers, e-cigarette, etc., is also increasing [1].

An unhealthy lifestyle comprised of sedentary habits is associated with noncommunicable diseases including obesity, cardiovascular diseases, musculoskeletal disorders, 
depression, and cancers [7]. Previous studies have identified that a lack of resources, increasing age, female gender, family commitments, and adverse socioeconomic conditions are some of the factors associated with physical inactivity and lifestyle in the Arab world [8-10].

Saudi Arabia is undergoing major developmental reforms, with an emphasis on reducing gender disparity and promoting a healthy lifestyle among the masses [11]. However, a high percentage of the Saudi population follows a sedentary lifestyle, and this is predicted to increase in the future $[5,10]$. Studies from Saudi Arabia on lifestyle have mainly focused on physical inactivity or obesity, without including eating habits or smoking $[5,10,12]$. Additionally, these have been hospital-based or institution-based studies conducted on specific populations, hence limiting the generalizability $[5,8,9]$. Therefore, it is imperative to measure the factors associated with an unhealthy lifestyle in a holistic manner, with representation from all ages and social classes. This study aimed to measure the prevalence and factors of an unhealthy lifestyle among the Saudi population aged 30 to 75 years in Riyadh, Saudi Arabia.

\section{Materials and Methods}

\subsection{Study Design and Setting}

This study was part of a large cross-sectional survey conducted in the capital city of Riyadh, Saudi Arabia, during 2015-2016. This survey aimed to measure the prevalence and correlates of chronic diseases among Saudi men and women aged 30 to 75 years [13]. In order to have representation from all five administrative regions of Riyadh city, 25 primary health care centers (PHCCs) were randomly selected from a list of 105 PHCCs by using a random number generator (RNG-RandomNumberGenerator.com). However, because of logistical issues we were able to include 18 PHCCs in the final analysis.

\subsection{Study Participants}

Different approaches were adapted to invite the general public for participation in the study. It was extensively advertised in the vicinity of the selected PHCC by placing posters in different places and distributing invitation letters at the selected PHCCs, large shopping malls nearby, local grocery stores, schools, and mosques. The inclusion criteria sought Saudi adults, aged 30 to 75 years, who were permanent residents of Riyadh, whereas non Saudis and pregnant women were excluded from the study. In total, 2997 (968 men and 2029 women) participants fulfilled the eligibility criteria, provided informed signed consent, and completed the interview.

\subsection{Data Collection Procedure and Measures}

Questionnaire-based interviews were conducted with each participant by a team of Arabic-speaking phlebotomists. The researchers trained the data collectors on conducting interviews, taking anthropometric measurements, and collecting blood samples. A detailed questionnaire was developed, with different sections focusing on physical, mental, and social health. The questionnaire for this study was comprised of sociodemographic characteristics (age, gender, marital status, occupation, income, housing type) and self-reported information on current and past smoking status (number of cigarettes, duration), physical activity, dietary history, and history of physician-diagnosed chronic diseases (including diabetes mellitus, hypertension, dyslipidemia, and arthritis).

\subsection{Physical Activity Questionnaire}

Physical activity (PA) was measured by the translated validated International Physical Activity Questionnaire (IPAQ-short) [14]. The items in the IPAQ-short are structured to calculate the metabolic equivalent of task (MET) in minutes per week. The MET minutes per week were calculated by multiplying the duration of activity in minutes by the number of days (activity done in a week) and then by multiplying with the pre-assigned values 
( walking $=3.3$ METs, moderate physical activity $(\mathrm{PA})=4.0 \mathrm{METs}$, and vigorous PA $=8.0$ ). The scores were added to calculate the total MET-minutes per week.

\subsection{Dietary Questionnaire}

The dietary part comprised questions about commonly consumed food items, including the quantity and frequency of intake in days/weeks/months/year. The quantity was inquired in grams by showing the quarter portion sizes of a standard serving plate. One portion was taken as equivalent to $80 \mathrm{gms}$ and an adult healthy diet should comprise of at least five portions $(>400 \mathrm{mg})$ of fruits and vegetables per day $[1,15]$. The information related to the remaining food items was utilized elsewhere.

\subsection{Definition of Healthy Lifestyle}

We have adapted the definition based on the WHO criteria for behavioral risk factors for cardiovascular diseases [1]. The outcome variable "Unhealthy lifestyle" based on behavioral risk factors, was defined as a person reporting $<1200$ MET-minutes per week, and/or eating $<5$ portions of vegetables and fruits per day ( $<400 \mathrm{gms})$ and/or being a regular smoker. Participants fulfilling two or all of the above criteria were labeled as having an "unhealthy lifestyle" [1,16,17].

\subsection{Barriers to Physical Activity and Healthy Eating}

A list of barriers to physical activity and healthy eating was compiled by retrieving questions from the previous literature and having a discussion with experts [18-20]. A validity assessment of all the variables was conducted by two independent researchers. The Arabic translated version of the questionnaire was pretested in the local community. Some of the items that were ambiguous or irrelevant were removed or rephrased according to the sociocultural setting. The final questions numbered 24 and were reviewed by two independent researchers. The barriers belonged to three broad categories, namely, behavioral, sociocultural and environmental. The question was phrased as follows: "Is a specific factor a barrier to you doing physical activity or opting for healthy eating?" The responses were measured as categorical, "yes" (1) vs. "no" (0). Barriers such as no skills to prepare healthy diet were inquired from women only, whereas barrier due to children was inquired from married women only. The Cronbach's alpha for the physical activity items was 0.72 and for healthy eating items it was 0.80 .

\subsection{Anthropometric Measurements}

A standard protocol was followed to measure anthropometric indices, which included weight measured using an electronic scale (Secca 220, Hamburg, Germany), and height measured using a stadiometer scale. The body mass index (BMI) was calculated using the formula weight $(\mathrm{kg})$ per height $\left(\mathrm{m}^{2}\right)$ [21].

\subsection{Ethical Considerations}

The study protocol was reviewed and approved by the Institutional Review Board, King Saud University (E-12-658) and the Institutional Review Board of the Ministry of Health, Dammam (IRB ID MOH0151), Saudi Arabia.

\section{Data Analysis}

The data were analyzed using Statistical Package for Social Sciences (SPSS)®version 21), Armonk, NY. IBM Corp. USA. A descriptive analysis was conducted to measure mean values and the standard deviations for the continuous variables and frequency percentages for the categorical variables. The Pearson correlation coefficient was calculated to measure the association between continuous variables. Chi-square and $p$-values were calculated for categorical variables and a $t$-test was utilized to measure the mean difference between continuous variables. Participants reporting an unhealthy lifestyle were coded as 1, vs. those reporting a healthy lifestyle were coded as 0 . Age was divided into categorical 
variables of 30-44 years, $45-59$ years, and 60-75 years. First, univariate analyses were performed to identify the gender differences in factors associated with an unhealthy lifestyle. Similarly, the occupation responses comprised of various professions ranging from doctor, engineer, military services, teacher, allied health services staff, security service, therefore the data was merged to make five major categories, namely, professional, clerical, unemployed, retired and homemaker. The barriers to healthy lifestyle include social and environmental barriers, therefore the male and female analysis was done separately.

Univariate analysis (without adjusting for potential confounders) was conducted separately for men and women. A unit change in the independent variable causing $>10 \%$ change in the estimates (dependent variable) is considered as significant. Hence, variables that were significant in a univariate analysis, suggesting biological plausibility (age, chronic diseases, obesity or causing a $\geq 10 \%$ difference in the estimates, were retained in the final model. Then multivariate binary logistic regression models based on the ENTER method were developed to identify statistically significant variables by generating adjusted odds ratios (aOR) and the $95 \%$ confidence interval (CI). All plausible interactions were confirmed before the development of the final model. The Hosmer-Lemeshow test was utilized to predict the goodness of the model fit. The level of significance was set to $p<0.05$.

\section{Results}

Table 1 shows the difference between men and women in terms of physical activity, healthy diet intake, and smoking prevalence. The median MET minutes per week (and interquartile ranges) for men and women were $1451(297,4158)$ and $1276(99,4350)$, respectively. A higher percentage of women reported PA $<1200$ MET $(49.8 \%)$ in comparison to men $(44.8 \%)$ with unadjusted odds ratio (UOR), showing women were 1.22-fold (1.05, 1.42) less likely to be active than men. The dietary habits indicated that $28 \%(n=272)$ of men and $25.5 \%(n=518)(p=0.53)$ of women were eating $<5$ portions of vegetables and/or fruit per day. Around one-third of men $(28 \%)$ were smokers, whereas women, with just $2 \%$ reporting as smokers, were at lower risk of smoking (UOR $0.03(0.02,0.04) p<0.001$ ). Cigarette was the most common form of smoking reported by men $(76 \%)$, whereas sheesha smoking was equally reported by both, men and women. Around $20 \%(n=7)$ of women had started smoking recently (in the last 1-2 years), whereas men were found to be chronic smokers (in some cases $>50$ years). Around $76 \%$ (33 out of 44 ) of women reported smoking $<10$ cigarettes per day, whereas the majority ( $41 \%$ ) of men smoked 10-20 cigarettes/day. Overall, an unhealthy lifestyle was more frequently reported by men as compared to women (56\% vs. $44 \%$ ) (UOR $1.49(1.28,1.74), p<0.001)$.

Table 1. The frequency of Saudi men and women reporting low levels of physical activity, inadequate dietary intake of vegetables and fruits, and smoking by age in Riyadh, Saudi Arabia.

\begin{tabular}{|c|c|c|c|c|c|}
\hline & \multicolumn{3}{|c|}{ Age Group (in Years) $\ddagger$} & \multirow{2}{*}{$\begin{array}{c}\text { Total }(n=2997) * \\
\text { Men }=968 * * \\
\text { Women }=2029\end{array}$} & \multirow{2}{*}{ Odds Ratio } \\
\hline & $30-44$ & $45-59$ & $60-75$ & & \\
\hline \multicolumn{6}{|c|}{ Low Physical activity ${ }^{1}$} \\
\hline Men & $247(56.9)$ & $126(29.0)$ & $61(14.1)$ & $434(44.8)$ & \multirow{3}{*}{$\begin{array}{c}1.0 \\
1.22(1.05,1.42)\end{array}$} \\
\hline Women & $507(50.1)$ & $357(35.3)$ & $147(14.5)$ & $1011(49.8)$ & \\
\hline Total & $754(52.2)$ & $483(33.4)$ & $208(14.4)$ & 1445 (48.2) & \\
\hline \multicolumn{6}{|c|}{$<5$ portions of vegetables } \\
\hline and truit/dz & $137(50.4)$ & $84(30.9)$ & $51(18.8)$ & $272(28.1)$ & \multirow{3}{*}{$\begin{array}{c}1.0 \\
0.93(0.74,1.17)\end{array}$} \\
\hline Men & $235(45.4)$ & $215(41.5)$ & $68(13.1)$ & $518(25.5)$ & \\
\hline $\begin{array}{c}\text { Women } \\
\text { Total }\end{array}$ & $372(47.1)$ & $299(37.8)$ & $119(15.1)$ & $790(26.3)$ & \\
\hline \multicolumn{6}{|c|}{ Regular Smoking ${ }^{3}$} \\
\hline Men & $209(78.0)$ & $46(17.2)$ & $13(4.9)$ & $268(27.7)$ & \multirow{3}{*}{$\begin{array}{c}1.0 \\
0.03(0.02,0.04)\end{array}$} \\
\hline Women & $31(70.5)$ & $10(22.7)$ & $3(6.8)$ & $44(2.2)$ & \\
\hline Total & $240(76.9)$ & $56(17.9)$ & $16(5.1)$ & $312(10.4)$ & \\
\hline
\end{tabular}

${ }^{*}$ Column percentage; $\ddagger$ Row percentage; ${ }^{* *}$ Men were $1.49(1.28,1.74)$ times more likely to have an unhealthy lifestyle. ${ }^{1}$ Low physical activity: $<1200 \mathrm{METs} \min /$ week $(p=0.04) .{ }^{2}<5$ portions equal to $<400 \mathrm{gms}(p>0.05) ;^{3} p=0.007$. 
Table 2 shows the univariate analysis with unadjusted odds ratio and $95 \%$ CI for factors significantly associated with an unhealthy lifestyle in men and women. The mean age $( \pm S D)$ of men and women in this study was $43.1( \pm 11.7)$ and $43.8( \pm 10.9)$ years, respectively. The majority of participants were married, with men mostly working as doctors, engineers, or in the military and women as teachers, secretaries, or allied health staff. The average number of children reported by married women was five $( \pm 3.0)$. About $27 \%(n=542)$ of women were postmenopausal. Age distribution found that more men aged $30-44$ years (63\% vs 55\%) reported unhealthy lifestyle, whereas, more women aged $60-75$ years (14\% vs $8.6 \%$ ) reported an unhealthy lifestyle. The mean BMI was not significantly different between the healthy and unhealthy groups for both men and women (men $29.7( \pm 6.7)$ vs. $29.7( \pm 6.2), p=0.99$ and women $31.4( \pm 6.2)$ vs. $31.5( \pm 6.8), p=0.67)$. A higher proportion of women were overweight $(37.6 \% \mathrm{vs} .29 .0 \%)$, whereas obesity was more common among men (56.7\% vs. $41.4 \%$ ).

Unadjusted odds ratio for the sociodemographic variables found that men aged 45-60 years [0.7, 95\% CI (0.5-0.9)] and those with household income of USD 2600-5000 [0.7, 95\% CI (0.4-0.9)] were 30 times less likely to report unhealthy lifestyle. In women, unadjusted odds ratio found that those aged 45-60 years and 61-75 years were $1.23(1.0,1.5)]$ and $1.84(1.4,2.5)$ times respectively, more likely to report unhealthy lifestyle. Homemaker and those working in clerical jobs were $2.1(1.1,4.0)$ times more likely to report unhealthy lifestyle.

Table 3 shows the frequency and significant difference between the barriers to physical activity and healthy diet in men and women. Generally, women reported fewer barriers than men; however, some barriers were equally reported by both men and women. Behavioral factors, like "lack of self-motivation" and "not enjoying physical activity," were reported by around one-third of men and women. Similarly, family commitments were reported as a barrier for both physical activity and healthy eating by both genders. Moreover, certain environmental barriers like having no access to affordable places for physical activity were mentioned by both men and women. 


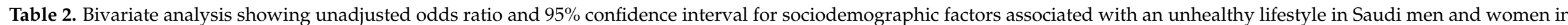
Riyadh, Saudi Arabia.

\begin{tabular}{|c|c|c|c|c|c|c|}
\hline \multirow{2}{*}{$\begin{array}{l}\text { Sociodemographic } \\
\text { Characteristics }\end{array}$} & \multicolumn{3}{|c|}{$\begin{array}{c}\text { Men } \\
N=968(\%)\end{array}$} & \multicolumn{3}{|c|}{$\begin{array}{c}\text { Women } \\
N=2029(\%)\end{array}$} \\
\hline & $\begin{array}{c}\text { Unhealthy Lifestyle } \\
n=523(54 \%)\end{array}$ & $\begin{array}{c}\text { Healthy Lifestyle } \\
n=445(46 \%)\end{array}$ & $\begin{array}{c}\text { Unadjusted Odds Ratio } \\
95 \% \text { CI }\end{array}$ & $\begin{array}{c}\text { Unhealthy Lifestyle } \\
894(44.1)\end{array}$ & $\begin{array}{c}\text { Healthy Lifestyle } \\
1135 \text { (55.9) }\end{array}$ & $\begin{array}{c}\text { Unadjusted Odds Ratio } \\
95 \% \text { CI }\end{array}$ \\
\hline \multicolumn{7}{|l|}{ Age (in Years) } \\
\hline $30-44$ & $329(62.9)$ & $247(55.5)$ & 1.0 & $456(51.0)$ & $664(58.5)$ & 1.0 \\
\hline $45-60$ & $138(26.4)$ & $147(33.0)$ & $0.7(0.5,0.9)$ & $314(35.1)$ & $373(32.9)$ & $1.23(1.0,1.5)$ \\
\hline $61-75$ & $56(10.7)$ & $51(11.5)$ & $0.8(0.5,1.2)$ & $124(13.9)$ & $98(8.6)$ & $1.84(1.4,2.5)$ \\
\hline \multicolumn{7}{|l|}{ Marital Status } \\
\hline Single & $58(11.1)$ & $44(9.9)$ & 1.0 & $69(7.7)$ & $77(6.8)$ & 1.0 \\
\hline Married/divorced & $465(88.9)$ & $401(90.1)$ & $0.9(0.6,1.33)$ & $825(92.3)$ & $1058(93.2)$ & $0.9(0.6,1.21)$ \\
\hline \multicolumn{7}{|c|}{ Participant's educational level } \\
\hline University or above & $377(72.1)$ & $337(75.7)$ & 1.0 & $384(43.0)$ & $492(43.3)$ & 1.0 \\
\hline High school or lower & $146(27.9)$ & $108(24.3)$ & $1.2(0.9,1.61)$ & $510(57.0)$ & $643(56.7)$ & $1.0(0.8,1.2)$ \\
\hline \multicolumn{7}{|c|}{$\begin{array}{l}\text { Educational level of spouse } \\
(\text { men }=866, \text { women }=1883)\end{array}$} \\
\hline University or above & $258(55.5)$ & $216(53.9)$ & 1.0 & $349(42.3)$ & $412(38.9)$ & 1.0 \\
\hline High school or lower & $207(44.5)$ & $185(46.1)$ & $0.9(0.7,1.22)$ & $476(57.7)$ & $646(61.1)$ & $0.8(0.7,1.04)$ \\
\hline \multicolumn{7}{|l|}{ Participant's occupation } \\
\hline Professional & $287(54.9)$ & $250(56.2)$ & 1.0 & $14(1.6)$ & $46(3.2)$ & 1.0 \\
\hline Clerical & $175(33.5)$ & $140(31.4)$ & $1.1(0.8,1.4)$ & $343(38.4)$ & $425(37.4)$ & $2.1(1.1,3.9)$ \\
\hline Unemployed & $14(2.7)$ & $7(1.6)$ & $1.7(0.7,4,4)$ & $35(3.9)$ & $68(6.0)$ & $1.3(0.6,2.8)$ \\
\hline Retired & $47(9.0)$ & $48(10.8)$ & $0.8(0.6,1,3)$ & $26(2.9)$ & $33(2.9)$ & $2.0(0.9,4.5)$ \\
\hline Homemaker & - & - & $\begin{array}{c}- \\
-0.0101\end{array}$ & $476(53.2)$ & $573(50.5)$ & $2.1(1.1,4.0)$ \\
\hline \multicolumn{7}{|l|}{$\begin{array}{c}\text { Spouse's occupation } \\
(\mathrm{men}=866, \text { women }=1883)\end{array}$} \\
\hline Professional & $362(77.8)$ & $326(81.3)$ & 1.0 & $175(21.2)$ & $226(21.4)$ & 1.0 \\
\hline Clerical & $79(20.0)$ & $55(13.7)$ & $1.3(0.9,1.9)$ & $301(36.5)$ & $317(30.0)$ & $1.2(1.0,1.6)$ \\
\hline Unemployed & $6(1.3)$ & $10(2.5)$ & $0.5(0.2,1.5)$ & $37(4.5)$ & $40(3.8)$ & $1.2(0.7,1.0 \mathrm{~S})$ \\
\hline Retired & $18(3.9)$ & $10(2.5)$ & $1.6(0.7,3.5)$ & $203(24.6)$ & $310(29.3)$ & $0.8(0.6,0.9)$ \\
\hline Military service & - & - & - & $109(13.2)$ & $165(15.6)$ & $0.9(0.6,1.2)$ \\
\hline
\end{tabular}


Table 2. Cont.

\begin{tabular}{|c|c|c|c|c|c|c|}
\hline \multirow{2}{*}{$\begin{array}{l}\text { Sociodemographic } \\
\text { Characteristics }\end{array}$} & \multicolumn{3}{|c|}{$\begin{array}{c}\text { Men } \\
N=968(\%)\end{array}$} & \multicolumn{3}{|c|}{$\begin{array}{c}\text { Women } \\
N=2029(\%)\end{array}$} \\
\hline & $\begin{array}{c}\text { Unhealthy Lifestyle } \\
n=523(54 \%)\end{array}$ & $\begin{array}{c}\text { Healthy Lifestyle } \\
n=445(46 \%)\end{array}$ & $\begin{array}{c}\text { Unadjusted Odds Ratio } \\
95 \% \text { CI }\end{array}$ & $\begin{array}{c}\text { Unhealthy Lifestyle } \\
894(44.1)\end{array}$ & $\begin{array}{l}\text { Healthy Lifestyle } \\
1135 \text { (55.9) }\end{array}$ & $\begin{array}{c}\text { Unadjusted Odds Ratio } \\
95 \% \text { CI }\end{array}$ \\
\hline \multicolumn{7}{|l|}{$\begin{array}{l}\text { Household Monthly Income } \\
\text { (U.S. Dollars) }\end{array}$} \\
\hline$\leq 2600$ & $190(36.3)$ & $155(34.8)$ & 1.0 & $74(8.3)$ & $87(7.7)$ & 1.0 \\
\hline $2600-5000$ & $239(45.7)$ & $230(51.7)$ & $0.7(0.4,0.9)$ & $245(27.4)$ & $326(28.7)$ & $0.9(0.6,1.2)$ \\
\hline$\geq 5000$ & $94(18.0)$ & $60(13.5)$ & $0.8(0.5,1.1)$ & $575(64.3)$ & $722(63.6)$ & $0.9(0.6,1.3)$ \\
\hline \multicolumn{7}{|l|}{ Body Mass Index $\left(\mathrm{kg} / \mathrm{m}^{2}\right)$} \\
\hline Normal $(<25.0)$ & $114(21.8)$ & $89(20.0)$ & 1.0 & $166(14.8)$ & $124(13.6)$ & 1.0 \\
\hline Overweight (25.0-29.9) & $181(34.6)$ & $183(41.1)$ & $0.8(0.5,1.1)$ & $319(28.5)$ & $270(29.7)$ & $0.8(0.6,1.2)$ \\
\hline Obese $(\geq 30.0)$ & $228(43.6)$ & $173(38.9)$ & $1.0(0.7,1.4)$ & $635(56.7)$ & $515(56.7)$ & $0.9(0.7,1.2)$ \\
\hline
\end{tabular}

Significant odds ratio and $95 \% \mathrm{CI}$ are given in bold. 
Table 3. The frequency of Saudi men and women reporting barriers for low physical activity and unhealthy eating habits in Riyadh, Saudi Arabia.

\begin{tabular}{|c|c|c|c|}
\hline Factors & $\begin{array}{c}\text { Men } \\
n=968(\%)\end{array}$ & $\begin{array}{c}\text { Women } \\
n=2029(\%)\end{array}$ & $p$-Value * \\
\hline \multicolumn{4}{|l|}{ Physical activity } \\
\hline No motivation to do physical activity & 309 (31.9) & $674(33.2)$ & 0.5 \\
\hline Don't enjoy physical activity & $260(26.9)$ & $520(25.6)$ & 0.5 \\
\hline Lack of appropriate skills to do physical activity & $295(30.5)$ & $495(24.4)$ & $<0.001$ \\
\hline No family support to do physical activity & $309(31.9)$ & $466(23.0)$ & $<0.001$ \\
\hline No friend/colleague support to do physical activity & $355(36.7)$ & $363(17.9)$ & $<0.001$ \\
\hline No family/ children support to do physical activity & $306(31.6)$ & $380(18.7)$ & $<0.001$ \\
\hline No time because of family commitments & $368(38.0)$ & $737(36.3)$ & 0.3 \\
\hline No information on physical activity & $299(30.9)$ & $343(16.9)$ & $<0.001$ \\
\hline No access to places to do physical activity & $299(30.9)$ & $653(32.2)$ & 0.5 \\
\hline No facilities that are affordable for physical activity & $254(26.2)$ & $541(26.7)$ & 0.8 \\
\hline No time to do physical activity because of job & $389(40.2)$ & $617(30.4)$ & $<0.001$ \\
\hline Feel self-conscious/shy doing exercise in front of others & $140(14.5)$ & $211(10.4)$ & 0.001 \\
\hline Not able to do physical activity because of weather & $394(40.7)$ & $400(19.7)$ & $<0.001$ \\
\hline Not able to do physical activity because of culture & $275(28.4)$ & $340(16.8)$ & $<0.001$ \\
\hline \multicolumn{4}{|l|}{ Healthy eating } \\
\hline Not motivated to eat a healthy diet & $313(32.3)$ & $450(22.2)$ & $<0.001$ \\
\hline Don't enjoy eating healthy food & $335(34.6)$ & $504(24.8)$ & $<0.001$ \\
\hline Don't have the skills to prepare or cook healthy foods ** & - & $267(13.2)$ & $<0.001$ \\
\hline No spouse/family support to eat a healthy diet & $296(30.6)$ & $290(14.3)$ & $<0.001$ \\
\hline No family/ children support to eat a healthy diet ** & $308(31.8)$ & $365(18.0)$ & $<0.001$ \\
\hline No friend/colleague support to eat a healthy diet & $377(38.9)$ & $274(13.5)$ & $<0.001$ \\
\hline Not enough information about a healthy diet & $366(37.8)$ & $318(15.7)$ & $<0.001$ \\
\hline No access to healthy foods & $388(40.1)$ & $262(12.9)$ & $<0.001$ \\
\hline Not able to afford healthy foods & $385(39.8)$ & $186(9.2)$ & $<0.001$ \\
\hline No time to prepare or eat healthy foods because of job & - & $384(18.9)$ & 0.03 \\
\hline $\begin{array}{l}\text { No time to prepare or eat healthy foods because of family } \\
\text { commitments }\end{array}$ & - & $323(15.9)$ & $<0.001$ \\
\hline
\end{tabular}

${ }^{*} p$ value denotes whether there is a difference in frequency of reported barrier between men and women; ${ }^{* *}$ Questions asked of married women only.

Moreover, there was a significant difference in the frequency of barriers reported by men and women. Men most commonly reported that "harsh weather" $(40.7 \%, n=394)$ and "lack of time because of job commitments" $(40.2 \%, n=389)$ were barriers to physical activity, whereas "no access to healthy food" $(40.1 \%, n=388)$ and "not able to buy healthy food" $(39.8 \%, n=385)$ were most commonly reported as barriers to healthy eating. Women most frequently reported "no time because of family commitments" $(36.3 \%, n=737)$, followed by "no motivation to do physical activity" $(33.2 \%, n=674)$ and "don't enjoy healthy food" $(24.8 \%, n=504)$, as barriers to physical activity and healthy eating, respectively.

Table 4 shows the multivariate binary logistic model with adjusted odds ratio and $95 \%$ confidence interval (CI) for men and women. In men it was found that those aged 
45-60 years [aOR 0.7, 95\% CI (0.5-0.9)] and 61-75 years [aOR 0.6, 95\% CI (0.4-1.0)] were at lower risk of reporting an unhealthy lifestyle, whereas men who do not enjoy physical activity [aOR 2.1, 95\% CI $(1.3,3.4)$ ], have no friend support to do physical activity [aOR 1.5, $95 \%$ CI (1.0 2.6)], or do not have enough information about a healthy diet [1.5, 95\% CI (1.0, 2.0)] were at higher risk of reporting an unhealthy lifestyle. In women aged 45-60 [aOR $1.3,95 \% \mathrm{CI}(1.1,1.7)$ ] and $61-75$ [aOR $2.4,95 \% \mathrm{CI}(1.7,2.3)$ ], lack of motivation [aOR 1.3, $95 \%$ CI $(1.1,1.7)$ ], feeling self-conscious while exercising [aOR 2.0, 95\% CI $(1.4,2.9)$ ], not enjoying healthy food [aOR 1.6, 95\% CI $(1.3,2.1)$ ], and no support from children in eating a healthy diet [aOR 1.4, 95\% CI $(1.1,1.8)]$ were at higher risk of reporting an unhealthy lifestyle (Table 3). The model was adjusted for education level, occupation, and BMI for both men and women.

Table 4. Multivariate logistic regression showing adjusted odds ratio and 95\% CI for factors associated with an unhealthy lifestyle among Saudi men and women in Riyadh, Saudi Arabia.

\begin{tabular}{|c|c|c|c|}
\hline Variables & $\begin{array}{l}\text { Crude Odds Ratio } \\
(95 \% \mathrm{CI})\end{array}$ & $\begin{array}{c}\text { Adjusted Odds Ratio * } \\
(95 \% \text { CI })\end{array}$ & $p$-Value \\
\hline \multicolumn{4}{|l|}{ Men } \\
\hline \multicolumn{4}{|l|}{ Age (in years) } \\
\hline $30-44$ & 1.0 & 1.0 & \\
\hline $45-60$ & $0.2(0.5,0.9)$ & $0.7(0.5,0.9)$ & 0.03 \\
\hline $61-75$ & $0.8(0.5,1.2)$ & $0.6(0.4,0.9)$ & 0.05 \\
\hline Do not enjoy physical activity & $2.3(1.7,3.1)$ & $2.1(1.3,3.4)$ & 0.003 \\
\hline No friend support to do physical activity & $1.9(1.5,2.5)$ & $1.5(1.0,2.6)$ & 0.05 \\
\hline Do not have enough information about healthy diet & $1.8(1.4,2.3)$ & $1.5(1.0,2.0)$ & 0.05 \\
\hline \multicolumn{4}{|l|}{ Women } \\
\hline \multicolumn{4}{|l|}{ Age (in Years) } \\
\hline $30-44$ & 1.0 & 1.0 & \\
\hline $45-60$ & $1.2(1.0,1.5)$ & $1.3(1.1,1.7)$ & 0.004 \\
\hline $61-75$ & $1.8(1.4,2.5)$ & $2.4(1.7,3.2)$ & $<0.001$ \\
\hline No motivation to do physical activity & $1.3(1.0,1.5)$ & $1.3(1.1,1.7)$ & 0.008 \\
\hline Feel self-conscious/shy doing exercise in front of others & $1.3(1.0,1.7)$ & $2.0(1.4,2.9)$ & $<0.001$ \\
\hline Do not enjoy eating healthy food & $1.6(1.3,1.9)$ & $1.6(1.3,2.1)$ & $<0.001$ \\
\hline No family support to eat a healthy diet & $1.4(1.1,1.7)$ & $1.4(1.1,1.8)$ & 0.01 \\
\hline
\end{tabular}

${ }^{*}$ Multivariate models were adjusted for education level, occupation, and BMI.

\section{Discussion}

Unhealthy lifestyle may comprise of several factors, however, we focused on the behavioral factors, namely, physical activity, diet and smoking [22,23]. Looking at the results, it appears that almost half $(47 \%)$ of the Saudi population is reporting an unhealthy lifestyle. The main contributing factors were low physical activity and unhealthy diet. Similar to previous studies, self-reported smoking prevalence was quite low in women, highlighting the fact that it may not be socially acceptable for women to smoke [24]. A significant population has already been diagnosed with a chronic disease or diseases and if combined with an unhealthy lifestyle, this may aggravate the existing health problems [25].

Overall, younger males and older aged women reported unhealthy lifestyle, and these differences suggest that no single strategy can be applied to the whole population [26]. The finding that older men were at less risk of an unhealthy lifestyle maybe because of successful efforts by healthcare workers [27]; however, it also suggests that health interventions with a focus on the young male population are required [28]. The opposite is required for women, because the number of women reporting an unhealthy lifestyle increased significantly after 60 years of age. This may be because of physiological changes in older women's lives: for example, menopause, the onset of chronic diseases, or changes 
in family structure [29]. Hence, we suggest that age-specific strategies, for example work place based for the younger population and home based plan for the older population may encourage and support healthy lifestyle.

Besides age, certain behavioral, sociocultural and environmental factors were significantly associated with lifestyle. Different behavioral change models are available to address lack of motivation and lack of confidence [30]. However, we believe that an integrated model, inclusive of behavioral change, social support and environmental support, is required to deal with the factors associated with an unhealthy lifestyle. An integrated behavior change model can help with increasing self-motivation, social understanding, and reinforcing positive behavior [31,32]. Techniques such as regular feedback, the demonstration of a positive behavior or attitude, behavior practice or rehearsal, and grading the tasks can help with overcoming a lack of motivation and improve self-determination [31,32].

In addition, the uptake and maintenance of healthy lifestyle requires a supportive environment and policies to allow motivation to become an inherent part of one's behavior [33]. Women participants reported that they feel self-conscious while exercising in front of others, which may be because of cultural restrictions or a lack of self-confidence [34]. Based on our findings we suggest that women require a specific allocated area and time to perform regular physical activity. This might instill confidence in women. According to the vision 2023, Saudi government is attempting to establish accessible exercise facilities in all major cities [12]. However, optimal and regular utilization of exercise facility is required to overcome these barriers. We found that, overall, $52 \%$ of the participants were obese; this is in close proximity to the future projected figures of $60 \%$ by 2022 [35]. Any behavior, to be sustainable, needs support from family, friends, and colleagues. The same stand for a healthy lifestyle: if there is positive support, physical activity and consuming a healthy diet can become enjoyable. However, negative peer pressure can be a distraction from regular physical activity and reason for unhealthy eating [36].

Women mostly report conflicting demands between work and childcare preventing them from adopting a healthy lifestyle [37]. The cultural norms expects that a Saudi woman will prioritize her family and household responsibilities over other engagements, such as going to a gymnasium for regular exercise [38]. While this may be culturally and socially approved, household chores will not always meet the recommended physical activity levels [39]. Hence, to overcome this barrier, an important initiative can be promoting PA at workplaces, which could be done by announcing health-promotion incentives (for example, free screening tests) or holding mandatory PA sessions on a regular basis [40]. Women mentioned that they do not have their children's support in preparing healthy foods; we suggest that healthy cooking competitions based on innovative recipes should be arranged at school and community level to promote healthy cooking and eating habits [41,42]. Additional initiatives may include availability of social support groups for buying healthy groceries and availability of babysitters at places of exercise. Past studies have reported that avoiding physical activity because of extreme temperatures was one of the most common barriers $[9,18,19]$. However, we did not find a significant association between extreme weather and lifestyle, maybe because of the large number of indoor gymnasiums recently opened for both men and women [12].

More than one-third of the male participants lacked information about a healthy diet. It is commonly known that the consumption of fruit and vegetables is associated with several health benefits; however, consumption remains low in both developing and developed countries [43]. One of the reasons for the low consumption of fruit and vegetables could be a lack of attractive advertisements and information. Various social media channels can be utilized to disseminate information about healthy eating. Easy recipes based on fruit and vegetables should be advertised so that people are encouraged to prepare and consume a healthy diet instead of fast food and energy drinks [43].

Several campaigns across the world are promoting healthy food [44]. However, healthy lifestyle policies can only be successfully implemented if all stakeholders are involved in the decision-making [44]. Therefore, we suggest that all concerned min- 
istries/institutes (health, education, social affairs. and recreation), join with the community to develop policies for promoting a healthy lifestyle.

\section{Strengths and Limitations}

The major strength of the current study is the large sample size, including various age groups, social classes and both working and nonworking population. We measured physical activity and dietary habits by utilizing a structured questionnaire. However, there were a few limitations. Although the PHCC were randomly selected, however the sample was self-selecting and we ended up with more number of women compared to men. It was a cross-sectional study, which prevents establishing any temporal relationship; thus, we cannot comment on the causality. We could not verify the smoking status in women, hence misreporting may have occurred. In addition, people belonging to rural areas may report different type of barriers, which we may have failed to capture. Hence results generalize to urban areas of Saudi Arabia.

\section{Conclusions}

A significant percentage of the Saudi population has an unhealthy lifestyle. The factors associated with an unhealthy lifestyle differ according to age and gender. The current study offers several implications for clinical and public health practices in the Gulf region. Policymakers, health workers, and social scientists should develop policies and programs, keeping in consideration the differences between men and women, young adults and the older population. Specific strategies for women should focus on social support groups for the elderly, along with self-motivation, the allocation of protected time with easy access to exercise facilities and a separate space for exercise is required to promote physical activity for the younger population. The increasing number of working people highlights the need for environmentally friendly policies for initiating exercise programs at workplaces.

Author Contributions: A.M.A. (AlJohara M. AlQuaiz) conceptualized the study, wrote the proposal, supervised data collection, manuscript writing; A.K. contributed towards proposal writing, supervised the data collection, cleaning of data and conducted analysis and manuscript writing, T.H.A. helped in data collection, manuscript writing and review; A.M.A. (Ali M. AlHazmi) supervised data collection, manuscript writing and manuscript review. R.Q. contributed towards proposal writing and reviewed the manuscript; K.M.A. contributed towards data collection, analysis and manuscript writing. All authors have read and agreed to the published version of the manuscript.

Funding: The study was funded by the Deanship of Scientific Research, Research Chairs program, King Saud University, Riyadh, Saudi Arabia.

Institutional Review Board Statement: The study protocol was reviewed and approved by the Institutional Review Board, King Saud University (E-12-658) and the Institutional Review Board of the Ministry of Health, Dammam (IRB ID MOH0151), Saudi Arabia.

Informed Consent Statement: Written informed consent has been obtained from the participant for this study.

Data Availability Statement: Data can be made available on special request to the principal Investigator.

Acknowledgments: We would like to thank the Ministry of Health, Saudi Arabia for allowing and facilitating us to conduct this study in the primary health care centers in Riyadh city. We would like to thank Bushra Abdul Wahab and Maha Younis for providing the logistical support during data collection. The authors thank the Deanship of Scientific Research and RSSU at King Saud University for their technical support.

Conflicts of Interest: The authors declare no conflict of interest. The funders had no role in the design of the study; in the collection, analyses, or interpretation of data; in the writing of the manuscript, or in the decision to publish the results. 


\section{References}

1. HEART Technical Package for Cardiovascular Disease Management in Primary Health Care: Healthy-Lifestyle Counselling; Geneva: World Health Organization; 2018 (WHO/NMH/NVI/18.1). Licence: CC BY-NC-SA 3.0 IGO. Available online: https: / / apps.who.int/iris/bitstream/handle/10665/260422/WHO-NMH-NVI-18.1-eng.pdf;sequence=1 (accessed on 7 July 2019).

2. Hallal, P.; Andersen, L.; Bull, F.; Guthold, R.; Haskell, W.; Ekelund, U. Global Physical Activity Levels: Surveillance Progress, Pitfalls, And Prospects. Lancet 2012, 380, 247-257. [CrossRef]

3. World Health Organization. Facts on Non Communicable Diseases. Available online: https://www.who.int/features/factfiles/ noncommunicable_diseases/en/ (accessed on 15 July 2019).

4. Kahan, D. Adult Physical Inactivity Prevalence in The Muslim World: Analysis Of 38 Countries. Prev. Med. Rep. 2015, 2, 71-75. [CrossRef]

5. Al-Hazzaa, H. Physical inactivity in Saudi Arabia revisited: A systematic review of inactivity prevalence and perceived barriers to active living. Int. J. Health Sci. 2018, 12, 50-64.

6. Saghaiana, S.; Mohammadib, H. Factors Affecting Frequency of Fast Food Consumption. J. Food Distrib. Res. $2018,49,1$.

7. Patterson, R.; McNamara, E.; Tainio, M.; de Sá, T.; Smith, A.; Sharp, S.; Edwards, P.; Woodcock, J.; Brage, S.; Wijndaele, K. Sedentary Behaviour And Risk of All-Cause, Cardiovascular And Cancer Mortality, And Incident Type 2 Diabetes: A Systematic Review And Dose Response Meta-Analysis. Eur. J. Epidemiol. 2018, 33, 811-829. [CrossRef]

8. Memish, Z.; El Bcheraoui, C.; Tuffaha, M.; Robinson, M.; Daoud, F.; Jaber, S.; Mikhitarian, S.; Al Saeedi, M.; AlMazroa, M.; Mokdad, A.; et al. Obesity And Associated Factors-Kingdom Of Saudi Arabia, 2013. Prev. Chronic. Dis. 2014, 11, E174. [CrossRef] [PubMed]

9. Al-Zalabani, A.; Al-Hamdan, N.; Saeed, A. The Prevalence Of Physical Activity And Its Socioeconomic Correlates In Kingdom Of Saudi Arabia: A Cross-Sectional Population-Based National Survey. J. Taibah Univ. Med Sci. 2015, 10, 208-215. [CrossRef]

10. Alshaikh, M.; Filippidis, F.; Al-Omar, H.; Rawaf, S.; Majeed, A.; Salmasi, A. The Ticking Time Bomb In Lifestyle-Related Diseases Among Women In The Gulf Cooperation Council Countries; Review Of Systematic Reviews. BMC Public Health 2017, 17, 536. [CrossRef]

11. Quality of Life Program 2020. Deliver Plan. Available online: https://vision2030.gov.sa/sites/default/files/attachments/QoL\% 20English_0.pdf (accessed on 17 September 2019).

12. Al-Hazzaa, H.M. Lifestyle Behaviors and Obesity: Brief Observations From The Arab Teens Lifestyle Study (ATLS) Findings. Obes. Open Access 2018, 4. [CrossRef]

13. AlQuaiz, A.; Siddiqui, A.; Kazi, A.; Batais, M.; Al-Hazmi, A. Sedentary Lifestyle And Framingham Risk Scores: A PopulationBased Study In Riyadh City, Saudi Arabia. BMC Cardiovasc. Disord. 2019, 19, 88. [CrossRef] [PubMed]

14. Lee, P.; Macfarlane, D.; Lam, T.; Stewart, S. Validity Of The International Physical Activity Questionnaire Short Form (IPAQ-SF): A Systematic Review. Int. J. Behav. Nut. Phys. Act. 2011, 8, 115. [CrossRef]

15. Wang, X.; Ouyang, Y.; Liu, J.; Zhu, M.; Zhao, G.; Bao, W.; Hu, F. Fruit And Vegetable Consumption And Mortality From All Causes, Cardiovascular Disease, And Cancer: Systematic Review And Dose-Response Meta-Analysis Of Prospective Cohort Studies. BMJ 2014, 349, g4490. [CrossRef]

16. Global Strategy on Diet, Physical Activity and Health: What Is Moderate-Intensity and Vigorous-Intensity Physical Activity? Geneva: World Health Organization. Available online: http://www.who.int/dietphysicalactivity/physical_activity_intensity/ en/ (accessed on 12 March 2019).

17. World Health Organization. Global Recommendations for Physical Activity for Health. 2010. Available online: https://www. who.int/dietphysicalactivity/background/en/ (accessed on 11 July 2019).

18. AlQuaiz, A.; Tayel, S. Barriers To A Healthy Lifestyle Among Patients Attending Primary Care Clinics At A University Hospital In Riyadh. Ann. Saudi Med. 2009, 29, 30-35. [CrossRef]

19. Benjamin, K.; Donnelly, T. Barriers and Facilitators Influencing The Physical Activity Of Arabic Adults: A Literature Review. Avicenna 2013, 8, 1-16. [CrossRef]

20. Musaiger, A.; Al-Mannai, M.; Tayyem, R.; Al-Lalla, O.; Ali, E.; Kalam, F.; Benhamed, M.; Saghir, S.; Halahleh, I.; Djoudi, Z.; et al. Perceived Barriers to Healthy Eating And Physical Activity Among Adolescents In Seven Arab Countries: A Cross-Cultural Study. Sci. World J. 2013, 232164. [CrossRef] [PubMed]

21. World Health Organization. Obesity: Preventing and Managing the Global Epidemic. Report on a WHO Consultation on Obesity, Geneva, 3-5 June 1997. Available online: http:/ / www.who.int/iris/handle/10665/63854 (accessed on 19 July 2019).

22. Mabry, R.; Koohsari, M.; Bull, F.; Owen, N. A Systematic Review of Physical Activity And Sedentary Behaviour Research In The Oil-Producing Countries Of The Arabian Peninsula. BMC Public Health 2016, 16, 1003. [CrossRef]

23. M Alqarni, S. A Review of Prevalence of Obesity n Saudi Arabia. J. Obes. Eat. Disord. 2016, 2, 2. [CrossRef]

24. Algabbani, A.M.; Almubark, R.; Althumiri, N.; Alqahtani, A.; BinDhim, N. The prevalence of cigarette smoking in Saudi Arabia in 2018. Food Drug Regul. Sci. J. 2018, 1, 1. [CrossRef]

25. AlQuaiz, A.; Siddiqui, A.; Qureshi, R.; Fouda, M.; AlMuneef, M.; Habib, F.; Turkistani, I. Women Health in Saudi Arabia: A Review of Non-communicable Diseases and Their Risk Factors. Pak. J. Med. Sci. 2014, 30, 422-431. [CrossRef]

26. Howlett, N.; Trivedi, D.; Troop, N.; Chater, A. Are Physical Activity Interventions for Healthy Inactive Adults Effective In Promoting Behavior Change And Maintenance, And Which Behavior Change Techniques Are Effective? A Systematic Review And Meta-Analysis. Transl. Behav. Med. 2019, 9, 147-157. [CrossRef] 
27. Al-Hazzaa, H.; AlMarzooqi, M. Descriptive Analysis of Physical Activity Initiatives for Health Promotion In Saudi Arabia. Front. Public Health 2018, 6, 329. [CrossRef] [PubMed]

28. Alahmed, Z.; Lobelo, F. Physical Activity Promotion in Saudi Arabia: A Critical Role for Clinicians and The Health Care System. J. Epidemiol. Glob. Health 2018, 7 (Suppl. 1), S7-S15. [CrossRef]

29. World Health Organization. Women, Ageing and Health: A Framework for Action. Focus on Gender. Available online: https:/ / www.who.int/ageing/publications/Women-ageing-health-lowres.pdf (accessed on 25 November 2020).

30. Taylor, D.; Bury, M.; Campling, N.; Carter, S.; Garfied, S.; Newbould, J.; Rennie, T. A Review of the Use of the Health Belief Model (HBM), the Theory of Reasoned Action (TRA), the Theory of Planned Behaviour (TPB) and the Trans-Theoretical Model (TTM) to Study and Predict Health Related Behaviour Change. 2006. Available online: https://www.nice.org.uk/guidance/ph6 /resources/behaviour-change-taylor-et-al-models-review (accessed on 15 January 2021).

31. Hagger, M.; Chatzisarantis, N. An Integrated Behavior Change Model for Physical Activity. Exerc. Sport Sci. Rev. 2014, 42, 62-69. [CrossRef]

32. Murray, J.; Brennan, S.; French, D.; Patterson, C.; Kee, F.; Hunter, R. Effectiveness of Physical Activity Interventions in Achieving Behaviour Change Maintenance In Young And Middle Aged Adults: A Systematic Review And Meta-Analysis. Soc. Sci. Med. 2017, 192, 125-133. [CrossRef]

33. Kelly, S.; Martin, S.; Kuhn, I.; Cowan, A.; Brayne, C.; Lafortune, L. Barriers and Facilitators to The Uptake and Maintenance of Healthy Behaviours By People At Mid-Life: A Rapid Systematic Review. PLoS ONE 2016, 11, e0145074. [CrossRef]

34. Almutairi, K.; Alonazi, W.; Vinluan, J.; Almigbal, T.; Batais, M.; Alodhayani, A.; Alsadhan, N.; Tumala, R.; Moussa, M.; Aboshaiqah, A.; et al. Health Promoting Lifestyle Of University Students In Saudi Arabia: A Cross-Sectional Assessment. BMC Public Health 2018, 18, 1093. [CrossRef]

35. Al Quwaidhi, A.; Pearce, M.; Critchley, J.; Sobngwi, E.; O'Flaherty, M. Trends and Future Projections of The Prevalence of Adult Obesity In Saudi Arabia, 1992-2022. East Mediterr. Health J. 2014, 20, 589-595. [CrossRef]

36. Vaughan, C.; Ghosh-Dastidar, M.; Dubowitz, T. Attitudes and Barriers to Healthy Diet and Physical Activity: A Latent Profile Analysis. Health Educ. Behav. 2017, 45, 381-393. [CrossRef] [PubMed]

37. Rajagopalasingam, V.; Fernando, R.L.S.; Ramanayake, U.B. Impacts of Perceived Role Demands on Work-Life Balance and Moderating Effects of Work Ethics: Evidence from Public Sector Professionals in Sri Lanka. Int. J. Bus. Manag. 2020, 15, 8. [CrossRef]

38. Moghadam, V. Women, Work and Family in The Arab Region: Toward Economic Citizenship. DIFI Fam. Res. Proc. 2013, 7, 1-20. [CrossRef]

39. Chastin, S.; De Craemer, M.; De Cocker, K.; Powell, L.; Van Cauwenberg, J.; Dall, P.; Hamer, M.; Stamatakis, E. How Does LightIntensity Physical Activity Associate with Adult Cardiometabolic Health and Mortality? Systematic Review With Meta-Analysis Of Experimental And Observational Studies. Br. J. Sports Med. 2019, 53, 370-376. [CrossRef]

40. Coulson, J.; McKenna, J.; Field, M. Exercising at Work and Self-Reported Work Performance. Int. J. Workplace Health Manag. 2008, 1, 176-197. [CrossRef]

41. Pem, D.; Jeewon, R. Fruit and Vegetable Intake: Benefits and Progress of Nutrition Education Interventions- Narrative Review Article. Iran. J. Public Health. 2015, 44, 1309-1321.

42. Tobey, L.; Manore, M. Social Media and Nutrition Education: The Food Hero Experience. J. Nutr. Educ. Behav. 2014, 46, 128-133. [CrossRef] [PubMed]

43. Jane, M.; Hagger, M.; Foster, J.; Ho, S.; Pal, S. Social Media for Health Promotion and Weight Management: A Critical Debate. BMC Public Health 2018, 18, 932. [CrossRef] [PubMed]

44. Rekhy, R.; McConchie, R. Promoting Consumption of Fruit and Vegetables For Better Health. Have Campaigns Delivered On The Goals? Appetite 2014, 79, 113-123. [CrossRef] 